А. М. Романова

Белорусский государственный технологический университет

\title{
ПРАКТИКО-ОРИЕНТИРОВАННОЕ ОБУЧЕНИЕ ПЕРЕВОДУ В НЕЯЗЫКОВОМ УЧЕБНОМ ВЫСШЕМ ЗАВЕДЕНИИ
}

\begin{abstract}
Обучение переводу научной и технической литературы в неязыковом УВО практико-ориентировано и предполагает овладение различными стратегиями перевода, научным стилем и логической последовательностью изложения сложного материала, достижением полноты изложения при отсутствии непосредственного контакта с получателем речи, терминологией на иностранном языке и обновление этого знания в свете изменения норм речи в стране носителей языка. Автор приводит грамматические особенности научно-технического стиля в современном английском языке; синтаксическую структуру научно-технического текста; стилеобразующие факторы английской научной речи; стратегию перевода. Рассмотрены изменения, которые претерпел английский язык за последние двадцать лет в процессе ассимиляции иностранцев в Англии. Приведены специализированные сайты для переводчиков с учетом формально-логического стиля изложения технической английской литературы. Также описаны особенности и нормы перевода (когезия, зевгма, перевод заимствований путем дефинирования), формирование у студентов неязыкового учреждения высшего образования компетенций, необходимых для практико-ориентированного перевода (академической, речевой, технической, информационно-поисковой, контекстуальной или трансформационной). Все стилистические и терминологические особенности перевода, равно как и грамматические явления, в научной и технической литературе сопровождаются многочисленными примерами.
\end{abstract}

Ключевые слова: научный стиль, когезия, силлепсис, английский язык, неязыковое УВО.

Для цитирования: Романова А. М. Практико-ориентированное обучение переводу в неязыковом учебном высшем заведении // Труды БГТУ. Сер. 4, Принт- и медиатехнологии. 2021. №. 2 (244). C. $142-146$.

\section{A. M. Romanova \\ Belarusian State Technological University \\ PRACTICE ORIENTED TRANSLATION TRAINING IN NON-LINGUISTIC UNIVERSITIES}

Training in the translation of scientific and technical literature in a non-linguistic University is practice-oriented and involves mastering various translation strategies, scientific style and logical sequence of presentation of complex material, achieving completeness of presentation in the absence of direct contact with the recipient of speech, terminology in a foreign language and updating this knowledge in the light of changes in the norms of speech in the country of native speakers. The author gives the grammatical features of the scientific and technical style in modern English; the syntactic structure of the scientific and technical text; style-forming factors of English scientific speech; translation strategy. The changes that the English language has undergone over the past twenty years in the process of assimilation of foreigners in England are considered. The article presents specialized websites for translators, taking into account the formal and logical style of presentation of technical English literature. It also describes the features and norms of translation (cohesion, zeugma, translation of borrowings by their definition), the formation of students of non-linguistic higher education institutions of the competencies necessary for practice-oriented translation (academic, speech, technical, information search, contextual or transformational). All stylistic and terminological features of translation, as well as grammatical phenomena, are accompanied by numerous examples in the scientific and technical literature.

Key words: scientific style, cohesion, syllepsis, English language, non-linguistic university.

For citation: Romanova A. M. Practice oriented translation training in non-linguistic universities. Proceedings of BSTU, issue 4, Print- and Mediatechnologies, 2021, no. 2 (244), pp. 142-146 (In Russian).

Введение. Процесс обучения переводу в неязыковом УВО происходит применительно к технической литературе, для которой характерны точность языка и формально-логический стиль изложения, инверсия (обратный порядок слов).
Перевод такой литературы практико-ориентирован, поэтому обучение ему предполагает формирование у студентов следующих компетенций: академической (language competence), речевой (speech competence), технической (technological competence), 
информационно-поисковой (information-mining competence), контекстуальной или трансформационной (transformational competence).

Основная часть. Научно-техническому стилю в современном английском языке присущи следующие грамматические особенности: широкое употребление множественного числа вещественных существительных (fats, oils, greases, steels, rare earths, sands, wools, gasolines, etc.); множественного числа в названиях инструментов (clippers, jointers, shears, dividers, compasses, trammels, etc.); использование предлога of для передачи видо-родовых отношений (the oxidizer of liquid oxygen, the fuel of kerosene); распространенность атрибутивных сочетаний со словами type, design, pattern, grade; повышенное использование причинно-следственных союзов и логических связок (since, therefore, it follows that, so, thus, it implies, involves, leads to, results in); широко употребляются безличные формы и конструкции с one. Например: "Protective clothing and dry-chemical-type fire extinguisher should be readily available in the area" [1].

Термины, обозначающие вещество и отвлеченное понятие, употребляются в обеих числовых формах без сдвига лексического значения и могут определяться числительными. Например: "Normally two horizontal permeabilities are measured". Объясняется это не ограничениями внутриязыкового порядка, а экстралингвистическими причинами [2].

Стройная и полная синтаксическая структура научно-технического текста объясняется важными стилеобразующими факторами научной речи (необходимость доходчивости и логической последовательности изложения сложного материала и традиционность). В них преобладают сложноподчиненные предложения. Немногочисленные простые предложения развернуты за счет однородных членов. Как правило, почти каждое существительное научного текста имеет постпозитивное или препозитивное определение, или и то и другое одновременно. Характерными для технических текстов являются препозитивные определительные группы, состоящие из целых цепочек слов: hydrogen-ion-potential recorders, anti-aircraft fire-control systems). Большое развитие определений этого типа связано с требованием точного ограничения используемых понятий. По этой же причине многие слова поясняются предложными, причастными, герундиальными и инфинитивными оборотами [3].

Как видно из представленных синтаксических, грамматических и морфологических особенностей данного текста, единственная функция научного стиля - интеллектуально-коммуникативная, другие функции факультативны. Научный стиль характерен для текстов, предназначенных для сообщения точных сведений из какой-либо специальной области и для закрепления процесса познания. Именно этим обстоятельством и определяется характер особенностей научного стиля в английском языке [4].

Таким образом, можно выделить следующие стилеобразующие факторы английской научной речи: необходимость доходчивости и логической последовательности изложения сложного материала; традиционность изложения; достижение полноты изложения при отсутствии непосредственного контакта с получателем речи [5].

Технические тексты необходимо переводить так, чтобы любой специалист в той или иной технической области понял, о чем идет речь. А это достигается за счет сохранения формально-логического стиля на протяжении всего перевода с английского языка на русский и наоборот. Таким образом, перевод текстов с техническим английским более тяготеет к научному переводу с соблюдением правил перевода в той или иной технической сфере.

Стратегии перевода: 1) понимание оригинала текста предшествует переводу (Л. Кэрол «Jabberwocky» - «Считалочки»); 2) перевод смысла, а не буквальный перевод (He is a regular ass. - Он круглый дурак (а не регулярный осел)); 3) жертвовать менее важными элементами текста ради большего успеха перевода; 4) значение целого важно (по совокупности элементов); 5) перевод должен соответствовать нормам языка, на который вы переводите текст [6].

При переводе научной и технической литературы, изданной сегодня в Великобритании, следует учитывать тот факт, что здесь проживают 66 млн человек, подавляющее большинство которых являются потомками эмигрантов в 1-3 поколении. В процессе ассимиляции иностранцев в Англии за последние 20 лет английский язык претерпел следующие изменения:

1) слова потеряли истинный смысл, при этом его не отменили, а просто их «люпают» где угодно, например: a terrific beauty - страшная красота; edgy feeling - напряжение, но edgy dress - писк моды; Delicious meal! - Классная штучка! (о новой вещи, шляпке, пр.); slum dunk (т. е. бросок в кольцо в баскетболе) - успешный; Subway and manners! Хорошие манеры и метро не совместимы! [7];

2) широко используются слова-хамелеоны (weasel words) и двусмысленности (ambiguity), например: nuts in your head - сумасшедший; requested floor (not wishing floor) - нужный этаж [8];

3 в в обиход вошли новые политкорректные термины и фразеологизмы, например: to microwave mentally - if you don't do it, then don't do it at all; generation XL - fat children / suffering from overweight; femini NAZI - aggressive feminism; invictus games - games for army men invalided some way (like Para Olympic Games) [9]; 
4) использование неологизмов, например: Brexit (брексит) и Grexit (грексит). Брексит (ударение на «е») образован из первых двух букв слова «Британия» и слова «ехit» (выход). Имеется в виду выход Великобритании из Евросоюза. Неологизм образован по аналогии со словом «Grexit», которым обозначается возможный выход Греции из ЕС [10];

5) постепенно появляются искусственно образованные термины и словосочетания, например: cherry-picking policy - все выборочно (досл. «по ягодке собирают»); nothing should be off the table - нужно все решить; behind the doors of \#10 (= in the Prime Minister's Cabinet) - решение на высшем уровне; a serious head scratching - серьезная головомойка; $A B C$ drinking или social drinking - пью только по праздникам (под праздниками понимаются годовщина "Anniversary", день рождения "Birthday", рождество "Christmas") [11];

6) частое употребление сокращений с новым значением, которые противоречат правилу «говори кратко, но четко» (“Be brief, but clear!”), например: GSM (good sense of humor) - хорошее чувство юмора [12];

7) вербальная коммуникация происходит с образованием слов-сокращений (Globish $=$ global English), использования искусственных фраз без смысловой нагрузки (It's not my cup of tea / piece of cake. - это не мое дело) [13].

Таким образом, человеку, работающему с языком, важно помнить следующее: 1) English changes every day due to social changes! - Английский язык претерпевает изменения ежедневно; 2) Кеер trace to / of the language!!! - Следи за изменениями в языке.

Важно знать нормы языка, на который ты переводишь, так как на нем ты и делаешь перевод. Чтобы получить наиболее правильный вариант перевода, необходимо освоить использование различных приемов и методов перевода текста. Приемы перевода - это конкретный подход к реальной трудности при переводе. К ним относятся: перефразирование, развернутый перевод, антонимический перевод, калькирование. Для практики выберите упражнения с одним и тем же словом на перевод. Официальный сайт $\mathrm{OOH}$ (www.un.org и unstats.un.org) предлагает архив текстов выступлений, докладов, резолюций на английском языке с переводом. Для практики достаточно выбрать такой документ и перевести его самостоятельно, а затем сравнить с официальным вариантом его перевода, чтобы увидеть возможные неточности и ошибки, которые вы допустили. Следует различать перевод буквальный / знаковый (interlinear) и смысловой (transformation), уметь делать коммунарный перевод (community interpreting), предполагающий достаточное владение терминологией для визита с иностранцем к врачу, в отели, т. д. [14]. нить:

$\mathrm{C}$ точки зрения стиля перевода нужно пом-

a) что система языка включает жанры, образность, перевод может быть газетным, официальным, торжественным, научным;

б) синхронный перевод включает и реферирование (компрессия или замена текста), и аннотирование (оценка текста и выборка по нему).

В каждом стиле есть свой жанр, допускающий или не предполагающий использование метафор, образных выражений и пр.

Согласно стандарту перевода ГОСТ 7.36.2006, образные фразеологизмы в английских научных текстах при переводе на русский язык становятся нейтральными. Например: the company took off another shoe to achieve the progress - ... приняла меры, ускорилась. При переводе одно предложение (англ.) будет передано лексически, а на другом языке (рус.) - синтаксически. Например: Nobody knows everything for sure1 - Никто ничего не знает наверняка! [4].

Вот лишь некоторые особенности перевода, на которые стоит обратить внимание: тема и рема, зевгма, перевод заимствований и соблюдение политкорректности.

Тема и рема. Любой текст должен быть связным и любое предложение имеет в себе то, что связывает его с контекстом - с предыдущим и последующим участками текста, т. е. в нем есть исходный посыл (от предыдущего) - «тема» и новая информация (к последующему) - «рема». Схема актуального членения русского предложения: «от темы к реме». Например: «Мальчик (тема) вышел в коридор (рема)». Далее повествование про коридор или про следование мальчика. Сравните «В коридор (тема) вышел мальчик (рема)»: далее повествование о том, что это за мальчик. В английском языке: "The boy came into a corridor" и "А boy came into the corridor". Часто в английском языке рема помещена в начале предложения (но не всегда). При переводе необходимо ориентироваться не на грамматику английского оригинала, а на контекст и правила русского языка [4].

Зевгма - это стилистический прием значимого нарушения синтаксической связи или смыслового согласования в словосочетании или между предложениями. Это использование слова в предложении сразу в нескольких значениях или синтаксическая ошибка, при которой объединение в одной конструкции нескольких отличающихся грамматически слов приводит к неправильному согласованию с другим словом. Зевгма использует слово в одном (буквальном) грамматическом, но другом (метафорическом) смысловом отношении к двум соседним словам. Например: "He lost everything there was to loose: his friend, his purse, his head and finally his reputation" - 
Он потерял все, что можно было потерять - друга, кошелек, голову и, наконец, репутацию [3].

Особенности перевода заимствований. Необходимо толковать при переводе заимствованные лексемы, так как представляется трудным подобрать им русский эквивалент. Такие лексемы, как lookism, sizism, fattism, weightism, лучше всего переводить путем их дефинирования, например, lookism - дискриминация по внешним данным, sizeism - дискриминация по физическим параметрам (ввиду того, что значение русской лексемы «размеризм» понятно не каждому), fattism - дискриминация полных людей, weightism - дискриминация по признаку физического веса, ablism - дискриминация по физическим способностям. С последним непосредственно связан другой термин-disabled, который рекомендуется использовать вместо invalid [3].

Социальные и культурные процессы в обществе влияют на смещение и дифференциацию семантических оттенков значения слова. Таким образом, из языка удаляются все те языковые единицы, которые задевают чувства, достоинство индивидуума, его расовую и половую принадлежности, возраст, состояние здоровья, социальный статус, внешний вид, а точнее - найти для них нейтральные и положительные эвфемизмы (т. е. смягченное выражение вместо резкого или нарушающего нормы приличия). Например: chairman - chairperson (председатель), spokesman - spokesperson (делегат), cameraman camera operator (оператор), foreman - supervisor (начальник) [14].

Процесс обучения переводу в неязыковом УВО происходит применительно к технической литературе. Технический английский язык точен и имеет формально-логический стиль изложения. В нем множество специализированных терминов, значение которых широко представлено в специализированных технических словарях, на сайтах для переводчиков (http///translation-blog.ru/knowhow) и сайтах-программах (www.multitran.ru). Последний позволяет сохранять Ваш вариант перевода терминов как авторский.

Заключение. Обучение переводу такой литературы предполагает владение языком оригинала и тем языком, на который мы переводим. Как видно из представленных синтаксических, грамматических и морфологических особенностей научно-технического текста, единственная функция научного стиля - интеллектуально-коммуникативная, другие функции факультативны. Научный стиль характерен для текстов, предназначенных для сообщения точных сведений из какой-либо специальной области и для закрепления процесса познания. Именно этим обстоятельством и определяется характер особенностей научного стиля в английском языке.

\section{Список литературы}

1. Володина М. Н. Когнитивно-информационная природа термина и терминологическая номинация: дисс. ... докт. филол. наук. М., 1998. 178 с.

2. Гореликова С. Н. Природа термина и некоторые особенности терминообразования в английском языке // Вестник ОГУ. 2002. № 6. С. 129-136.

3. Комиссаров В. Н. Теория перевода (лингвистические аспекты): учеб. для ин-тов и фак. иностр. яз. М.: Высш. школа, 1990. 253 с.

4. Латышев Л. К. Курс перевода: эквивалентность перевода и способы ее достижения. М.: Международные отношения, 1981. 300 с.

5. Лотте Д. С. Образование системы научно-технических терминов // Основы построения научнотехнической терминологии. 1961. $160 \mathrm{c.}$

6. Миньяр-Белоручев Р. К. Общая теория перевода и устный перевод. М.: Воениздат, 1980. 237 с.

7. Цвиллинг М. Я. Научная литература: язык, стиль, жанры. М.: Наука, 1985. 336 с.

8. Основы теории коммуникации: учебник / под ред. М. А. Василика. М.: Гардарики, 2003. 615 с.

9. Комиссарова В. Н. Проблемы перевода в свете теории коммуникации // Вопросы теории перевода в зарубежной лингвистике. М.: Международные отношения, 1978. 232 с.

10. Пумпянский А. Л. Лексические закономерности научной и технической литературы. Англорусские эквиваленты: учеб. пособие. Калининград: КГУ, 1980. 83 с.

11. Стрелковский Г. М., Латышев Л. К. Научно-технический перевод. М.: Просвещение, 1980. $175 \mathrm{c}$.

12. Talbot J., Taylor. Linguistic Theory and Structural Stylistics. Oxford: Pergamon Press, 1981. 111 p.

13. Синдеев Ю. Англо-русский политехнический словарь. Ростов-на-Дону: Феникс, 2002.831 с.

14. Hornby A. S., Cowie A. P., Gimson A. C. Oxford Advanced Learner's Dictionary of Current English. London: Oxford Univ. Press, 1980. 1055 p.

\section{References}

1. Volodina M. N. Kognitivno-informatsionnaya priroda termina i terminologicheskaya nominatsiya. Dis. ... dokt. filol. nauk [Cognitive-informational nature of the term and terminological nomination. Diss. DSc (Philology)]. Moscow, 1998. 178 p. 
2. Gorelikova S. N. The nature of the term and some features of term formation in the English language // Vestnik OGU [OSU Bulletin], 2002, no. 6, pp. 129-136 (In Russian).

3. Komissarov V. N. Teoriya perevoda (lingvisticheskie aspekty) [Translation theory (linguistic aspects)]. Moscow, Vysshaya shkola Publ., 1990. 253 p.

4. Latyshev L. K. Kurs perevoda: ekvivalentnost' perevoda i sposoby eye dostizheniya [Translation Course: Translation Equivalence and ways to achieve it]. Moscow, Mezhdunarodnyye otnosheniya Publ., 1981. 300 p.

5. Lotte D. S. Formation of a system of scientific and technical terms. Osnovy postroyeniya nauchno-tekhnicheskoy terminologii [Fundamentals of the construction of scientific and technical terminology], 1961. $160 \mathrm{p}$. (In Russian)

6. Min'yar-Beloruchev R. K. Obshchaya teoriya perevoda i ustnyy perevod [General theory of translation and interpretation]. Moscow, Voyenizdat Publ., 1980. 237 p.

7. Cvilling M. Ya. Nauchnaya literatura: yazyk, stil', zhanry [Scientific literature: language, style, genres]. Moscow, Nauka Publ., 1985. 336 p.

8. Vasilik M. A. Osnovy teorii kommunikatsii [Fundamentals of communication theory]. Moscow, Gardariki Pub., 2003. 615 p.

9. Komissarova V. N. Translation problems in the light of communication theory. Voprosy teorii perevoda $v$ zarubezhnoy lingvistike [Questions of translation theory in foreign linguistics], 1978. 232 p. (In Russian)

10. Pumpyanskij A. L. Leksicheskiye zakonomernosti nauchnoy i tekhnicheskoy literatury. Anglo-russkiye ekvivalenty [Lexical patterns of scientific and technical literature. English-Russian equivalents]. Kaliningrad, KGU Publ., 1980. 83 p.

11. Strelkovskiy G. M., Latyshev L. K. Nauchno-tekhnicheskiy perevod [Scientific and technical translation]. Moscow, Prosveshcheniye Publ., 1980. 175 p. $111 \mathrm{p}$.

12. Talbot J., Taylor. Linguistic Theory and Structural Stylistics. Oxford, Pergamon Press Publ., 1981.

13. Sindeev Yu. Anglo-russkiy politekhnicheskiy slovar' [English-Russian Polytechnic Dictionary]. Rostovna-Donu, Feniks Publ., 2002. 831 p.

14. Hornby A. S., Cowie A. P., Gimson A. C. Oxford Advanced Learner's Dictionary of Current English. London, Oxford Univ. Press Publ., 1980. 1055 p.

\section{Информация об авторе}

Романова Анна Михайловна - кандидат педагогических наук, доцент кафедры межкультурных коммуникаций и технического перевода. Белорусский государственный технологический университет (220006, г. Минск, ул. Свердлова, 13a, Республика Беларусь). E-mail: annaromanova@yahoo.com

\section{Information about the author}

Romanova Anna Mikhaylovna - PhD (Pedagogics), Assistant Professor, the Department of Intercultural Communication and Technical Translation. Belarusian State Technological University (13a, Sverdlova str., 220006, Minsk, Republic of Belarus). E-mail: annaromanova@yahoo.com 